www.jmscr.igmpublication.org

Impact Factor 5.244

Index Copernicus Value: 83.27

ISSN (e)-2347-176x ISSN (p) 2455-0450

crossref DOI: _https://dx.doi.org/10.18535/jmscr/v4i10.65

\author{
Journal Of Medical Science And Clinical Research \\ IGM Publication \\ An official Publication of IGM Publication
}

\title{
Sonographic Evaluation of Solitary Thyroid Nodule with Pathologic Correlation
}

\author{
Authors \\ Nandan Kumar L. $\mathrm{D}^{1}$, Shilpa $\mathrm{N}^{2}$ \\ ${ }^{1}$ Consultant Radiologist, Malnad Hi-tech diagnostic centre, Shimoga, Karnataka, India \\ ${ }^{2}$ Pathologist, Shimoga Institute of Medical Sciences. Shimoga, Karnataka, India \\ Corresponding Author \\ Shilpa N \\ Email:drshilpanandan@gmail.com
}

\begin{abstract}
Thyroid nodules are most common problems encountered in clinical practice. There should be proper diagnostic work up to select patients for surgical intervention, who have high chances of harbouring malignancy in the nodule. Ultrasound plays major role in differentiating benign and malignant nodule. Present study is undertaken to identify the various imaging features in thyroid nodules that are associated with benignity and malignancy. To know sensitivity, specificity, positive predictive value (PPV) and negative predictive value (NPV) of ultrasonography as diagnostic module for solitary thyroid nodules. Materials and Methods: Present study included 60 patients with solitary thyroid nodule. Transverse and longitudinal real time ultrasound imaging of thyroid gland were performed. Ultrasound appearances of size, shape echogenicity, internal architecture, margins, halo, vascularity, presence or absence of lymph nodes were observed. On the basis of which nodule was classified in to benign or malignant /suspicious for malignancy. Pathological reports were considered standard for comparison. Diagnostic value of ultrasonography was calculated by sensitivity specificity, positive predictive value and negative predictive value. Result and discussion: 60 thyroid nodules were evaluated, with Male: Female ratio of 1:5.6. Age of patients ranged from 18 to 63 years with mean age of $36+8.2$ years. Sensitivity, specificity, PPV and NPV of ultrasonography as diagnostic tool are 70.0\%, 98\%, 87.5\%, 96\% respectively. These statistics correlate well with previous studies. Conclusion: Ultrasound is a sensitive and specific modality in assessment of thyroid nodules with good overall accuracy.
\end{abstract}

Keywords- Solitary thyroid nodule, Colloid nodule, Papillary carcinoma, Follicular adenoma, Ultrasonography.

\section{INTRODUCTION}

Thyroid nodules are most common problems encountered in clinical practice. ${ }^{[1]}$ They are found in 4 to $8 \%$ of adults on palpation. ${ }^{[2]}$ About 70 to $80 \%$ of solitary thyroid nodules are asymptomatic and patients present with lump and about 10 to $15 \%$ of cases are detected incidentally on neck ultrasonography. ${ }^{[3], ~[4] ~ A m o n g s t ~ t h e s e ~ m a j o r i t y ~ o f ~}$ solitary thyroid nodules are benign and incidence of malignancy in less than $10 \%{ }^{[5]}$. There should be proper diagnostic work up to select patients for surgical intervention, who have high chances of harbouring malignancy in the nodule. According to American Thyroid Association guidelines Ultra- 
sonography (USG) should be performed in all patients with suspected thyroid nodules. Other adjunctive tests are thyroid function tests and fine needle aspiration cytology. ${ }^{[1]}$ Ultrasound plays major role in differentiating benign and malignant nodule. The morphological criteria which are considered to differentiate benign and malignant include echogenicity, internal architecture, shape, halo, vascularity, presence or absence of lymph nodes. Although overlapping and combination of features exists. ${ }^{[6]}$ Present study is undertaken to identify the various imaging features in thyroid nodules that are associated with benignity and malignancy. To know sensitivity, specificity, positive predictive value (PPV) and negative predictive value (NPV) of ultrasonography as diagnostic module for solitary thyroid nodules

\section{Material and Methods}

Present study included 60 patients with solitary thyroid nodule. Patient's demographic data, clinical data were obtained. Complete clinical examination was done. Transverse and longitudinal real time ultrasound imaging of thyroid gland were performed. Ultrasound appearances of size, shape echogenicity, internal architecture, margins, halo, vascularity, presence or absence of lymph nodes were observed. On the basis of above mentioned features the nodule was classified in to benign or malignant /suspicious for malignancy. In most of the cases histopathological correlation was available in on available cases cytology was considered as standard. Patients with multiple nodules and diffuse lesions and also cases with no pathological follow up were excluded from study. Descriptive analysis was done for imaging characteristic features. Diagnostic value of ultrasonography was calculated by sensitivity specificity, positive predictive value and negative predictive value.

\section{RESULTS}

A total of 60 patients with solitary thyroid nodules were evaluated. Amongst these 51 were females and 9 were males with Male: Female ratio of 1:5.6. Age of patients ranged from 18 to 63 years with mean age of $36+8.2$ years. Size of the nodules ranged from $0.5 \mathrm{~mm}$ to $5.2 \mathrm{~cm}$ with mean of $3.2+0.8 \mathrm{~cm}$. On ultrasonography 52 cases were benign and 8 cases were malignant. Benign lesions include colloid nodule, colloid nodule with cystic degeneration, simple cyst, follicular adenoma. Malignant nodules include papillary carcinoma and follicular carcinoma. Morphological imaging characteristics are shown in table 1.

Table. No. 1 Morphological imaging characteristics of thyroid nodules

\begin{tabular}{|l|l|l|}
\hline $\begin{array}{l}\text { Morphologic } \\
\text { features }\end{array}$ & Parameters & $\begin{array}{l}\text { No of cases-n } \\
(\%)\end{array}$ \\
\hline \multirow{5}{*}{ Shape } & Round & $8(13.33 \%)$ \\
\cline { 2 - 3 } & Oval & $48(80 \%)$ \\
\cline { 2 - 3 } & Irregular & $4(6.67 \%)$ \\
\hline \multirow{2}{*}{ Margin } & Regular & $50(83.33 \%)$ \\
\cline { 2 - 3 } & Irregular & $10(16.67 \%)$ \\
\hline \multirow{2}{*}{$\begin{array}{l}\text { Internal } \\
\text { architecture }\end{array}$} & Cystic & $14(23.33 \%)$ \\
\cline { 2 - 3 } & Solid & $35(58.33 \%)$ \\
\cline { 2 - 3 } & Complex & $11(18.33 \%)$ \\
\hline \multirow{5}{*}{ Calcification } & Coarse & $7(11.67 \%)$ \\
\cline { 2 - 3 } & Micro & $3(5 \%)$ \\
\cline { 2 - 3 } & Absent & $50(83.33 \%)$ \\
\hline \multirow{5}{*}{ Halo } & Present & $50(83.33 \%)$ \\
\cline { 2 - 3 } & Absent & $10(16.67 \%)$ \\
\hline \multirow{5}{*}{ Vascularity } & Peripheral & $40(66.66 \%)$ \\
\cline { 2 - 3 } & Central & $10(16.67 \%)$ \\
\cline { 2 - 3 } & Absent & $10(16.67 \%)$ \\
\hline \multirow{2}{*}{ Lymphadenopathy } & Present & $6(10 \%)$ \\
\cline { 2 - 3 } & Absent & $54(90 \%)$ \\
\hline
\end{tabular}

On pathology there were 10 malignant cases amongst 60 solitary nodules. Two cases of colloid nodule with cystic degeneration proved to be papillary carcinoma and one case of follicular adenoma turned out to be follicular variant of papillary carcinoma on histopathology. One case of colloid nodule was misdiagnosed as papillary carcinoma. Sensitivity, specificity, PPV and NPV of ultrasonography as diagnostic tool is given in table 2.

Table 2 Sensitivity, specificity, PPV and NPV of ultrasonography

\begin{tabular}{|l|l|l|l|l|}
\hline \multirow{2}{*}{ USG } & Sensitivity & Specificity & PPV & NPV \\
\cline { 2 - 5 } & $70.0 \%$ & $98 \%$ & $87.5 \%$ & $96 \%$ \\
\hline
\end{tabular}


Table 3 Sonographic features in pathologically confirmed cases of malignancy

\begin{tabular}{|l|l|l|}
\hline Morphologic features & Parameters & \\
\hline \multirow{4}{*}{ Shape } & Round & $4(40 \%)$ \\
\cline { 2 - 3 } & Oval & $1(10 \%)$ \\
\cline { 2 - 3 } & Irregular & $5(50 \%)$ \\
\hline \multirow{3}{*}{ Margin } & Regular & $1(10 \%)$ \\
\cline { 2 - 3 } & Irregular & $9(90 \%)$ \\
\hline \multirow{4}{*}{ Calchogenicity } & Hypoechoic & $7(70 \%)$ \\
\cline { 2 - 3 } & Mixed & $3(30 \%)$ \\
\hline \multirow{3}{*}{ Halo } & Coarse & 0 \\
\cline { 2 - 3 } & Micro & $3(30 \%)$ \\
\cline { 2 - 3 } & Absent & $7(70 \%)$ \\
\hline Vascularity & Present & $1(10 \%)$ \\
\cline { 2 - 3 } & Absent & $9(90 \%)$ \\
\hline \multirow{2}{*}{ Lymphadenopathy } & Peripheral & $1(10 \%)$ \\
\cline { 2 - 3 } & Central & $8(80 \%)$ \\
\cline { 2 - 3 } & Absent & $1(10 \%)$ \\
\cline { 2 - 3 } & Present & $2(20 \%)$ \\
\cline { 2 - 3 } & Absent & $8(80 \%)$ \\
\hline
\end{tabular}

Cystic nodules: Cystic nodules on ultrasound included 14 cases. Majority of them were colloid goitre with degeneration and colloid cyst. There was single case of simple cyst, which drained clear fluid on aspiration. Three cases of papillary carcinoma presented as cystic mass. One case of colloid goitre with haemorrhage was later proved as papillary carcinoma on histopathology.

Solid nodules: Sonologically detected solid nodules were hyperplastic adenomatoid nodules and follicular adenoma. A case of follicular adenoma, on histopathology turned out to be follicular variant of papillary carcinoma.

Mixed nodules: majority of mixed lesions were colloid goitre with secondary changes. One each case of follicular carcinoma and papillary carcinoma presented with mixed architecture. One case of colloid goitre with cystic degeneration later proved as follicular carcinoma and papillary carcinoma with mixed architecture later confirmed as colloid goitre on pathological examination.

Out of 6 cases with lymph node positivity only two had papillary carcinoma metastasis and rest of them showed reactive hyperplasia.

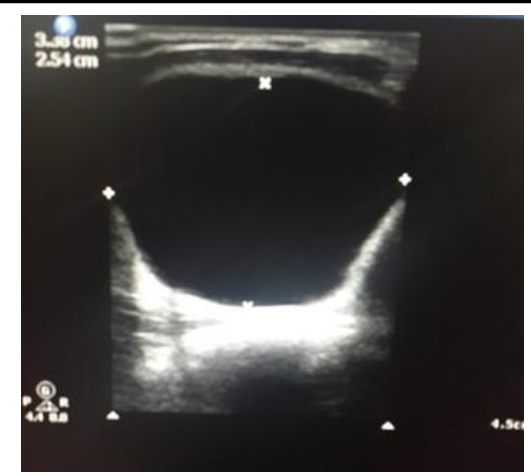

Figure 1 Simple cyst of thyroid
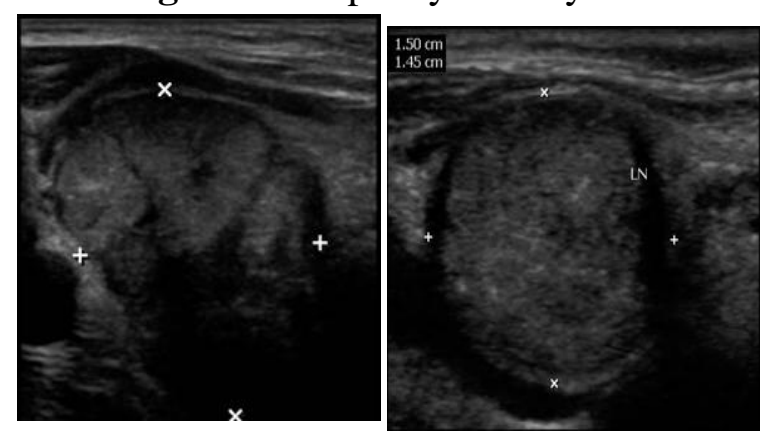

Figure 2 Papillary carcinoma thyroid (a) with lymph node metastasis (b)

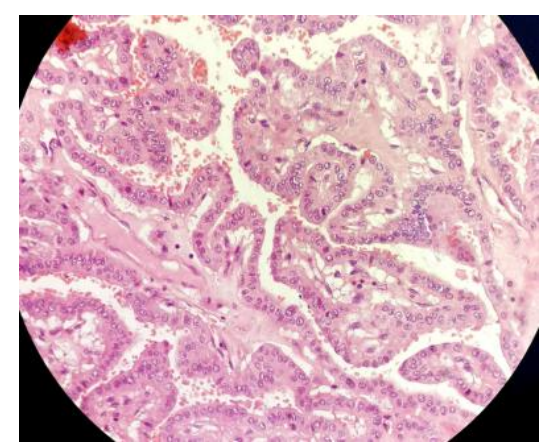

Figure 3 Histopathology of papillary carcinoma

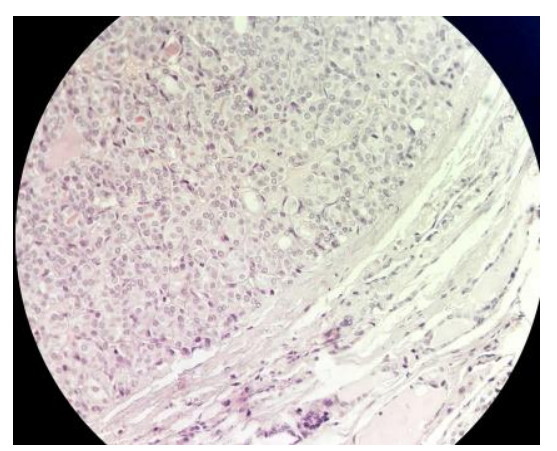

Figure 4 Follicular adenoma thyroid

\section{DISCUSSION}

In the present study of solitary thyroid nodules, the occurrence among males and females was 1:5.6. Age of patients ranged from 18 to 63 years with mean age of $36 \pm 8.2$ years. These demographic 
results correlate well with previous studies. ${ }^{[7]-[9]} \mathrm{On}$ ultrasound examination amongst 60 solitary thyroid nodules $13.3 \%$ which is similar to few studies. The features suggestive towards benignity are anechoic or mixed echogenicity, round with regular margins, presence of halo, coarse calcification peripheral vascularity and absence of lymph nodes. The features such as irregular margins, hypoechoic, micro calcification, central vascularity, absence of halo, presence of lymph nodes suggest the possibility of malignancy. However, in present study there were overlapping features, like few nodules with oval shape, regular margins, absent vascularity were positive for malignancy. Therefore with combination of features with adjunctive cytology will help in proper diagnosis. These imaging features are similarly described in previous studies. [1],[10],[11] The sensitivity, specificity, PPV and NPV are in accordance with most of the previous studies. [4], [10], [7], [12] Present study is limited by the individual morphological feature diagnostic value in differentiating benign and malignancy as the sample size is low.

\section{CONCLUSION}

Ultrasound is a sensitive and specific modality in assessment of thyroid nodules with good overall accuracy. Ultrasound is the most useful imaging modality for evaluation of solitary thyroid nodules, as it is easily available, has superior resolution, helps classify lesions, detects non palpable nodules and guides for fine needle aspiration of suspicious nodules. There are few overlapping imaging features of malignancy which is overcome by combining with fine needle aspiration cytology.

\section{REFERENCES}

1. Ali A, Jasir M. Sonological and Pathological Evaluation of Solitary Nodule Thyroid. IOSR J Dental Med Sci 2013;16(3):1-8

2. Wiest PW, Hartshorne MF, Inskip PD, et al. Thyroid palpation versus high-resolution thyroid ultrasonography in the detection of nodules. J Ultrasound Med 1998;17: 487496.
3. Carroll BA. Asymptomatic thyroid nodules: incidental sonographic detection. AJR Am J Roentgenol 1982;138:499-501.

4. Anuradha Kapali, Jaipal B R, Raghuram P, Ravindra Bangar, Sateesh Kumar Atmakuri. Role of ultrasonogra- phy in thyroid nodules with pathological correlation. Int $\mathbf{J}$ Contemporary Med Res 2016;3(5):1451-3.

5. Risk of malignancy in non-palpable thyroid nodule;predictive value of ultrasound and color Doppler features.J clin Endocrinol metab 2002;87(5):1941-1946.

6. Hoang JK, Lee WK, Lee M, Johnson D, Farrell S. US features of thyroid malignancy: pearls and pitfalls. Radiographics 2007:27:847- 65 .

7. Mallikarjunappa B, Ashish S R, Ultrasound Evaluation of Thyroid Nodules and its Pathological Correlation, JIMSA 2014;27 (1);8-11.

8. Seiberling KA, Dutra JC, Grant $\mathrm{T}$ et al: Role of intrathyroidal calcification detected on ultrasound as a marker of malignancy. Laryngoscope 2004; 114(10):1753-7.

9. Kimoto et al the efficiency of performing FNAC following mass gaining for thyroid tumors to avoid unnecessary surgery, surge today 1999;29(9) 880-3.

10. ChanBK, Desser TS, McDougall IR, Weigel RJ, Jeffrey RB Jr. Common and uncommon sonographic features of papillary thyroid carcinoma. J Ultrasound Med2003; 22(10): 1083-90.

11. TakiS, Terahata S, Yamashita R, et al. Thyroid calcifications: sonographic patterns and incidence of cancer. Clin Imaging2004; 28(5):368-371.

12. Sreeramulu P N,Venkatachalapathy T S, Prathima S, A Prospective Study Of Clinical, Sonological And Pathological Evaluation Of Thyroid Nodule. J Biosci Tech 2012; 3 (1):474- 78. 